\title{
Article \\ Flux Growth and Properties of Volatile Bromine-Containing UV Nonlinear Optical Crystal $\mathrm{K}_{3} \mathrm{~B}_{6} \mathrm{O}_{10} \mathrm{Br}$
}

\author{
Huaiyu Hu ${ }^{1,2,+}$, Chen Zhou ${ }^{1,+}{ }^{+}$Jiahao Jiao ${ }^{1,2}$, Siru Guo ${ }^{1,2}$, Yanna Chen ${ }^{1}$ and Min Zhang ${ }^{1, *(1)}$ \\ 1 Xinjiang Key Laboratory of Electronic Information Materials and Devices, Xinjiang Technical Institute of \\ Physics \& Chemistry, Chinese Academy of Sciences, Urumqi 830011, China; huhuaiyu960719@163.com (H.H.); \\ chenzhou@hit.edu.cn (C.Z.); h8glass@163.com (J.J.); guosiru18@mail.ucas.ac.cn (S.G.); \\ ynchenaa@163.com (Y.C.) \\ 2 University of the Chinese Academy of Sciences, Beijing 100049, China \\ * Correspondence: zhangmin@ms.xjb.ac.cn \\ + These authors contributed equally to this work.
}

Citation: Hu, H.; Zhou, C.; Jiao, J.; Guo, S.; Chen, Y.; Zhang, M. Flux Growth and Properties of Volatile Bromine-Containing UV Nonlinear Optical Crystal $\mathrm{K}_{3} \mathrm{~B}_{6} \mathrm{O}_{10} \mathrm{Br}$. Crystals 2022, 12, 33. https://doi.org/ $10.3390 /$ cryst 12010033

Academic Editors: Zsuzsanna Szaller and Shanpeng Wang

Received: 1 December 2021

Accepted: 22 December 2021

Published: 26 December 2021

Publisher's Note: MDPI stays neutral with regard to jurisdictional claims in published maps and institutional affiliations.

Copyright: (c) 2021 by the authors. Licensee MDPI, Basel, Switzerland. This article is an open access article distributed under the terms and conditions of the Creative Commons Attribution (CC BY) license (https:// creativecommons.org/licenses/by/ $4.0 /)$.

\begin{abstract}
A UV Nonlinear optical (NLO) crystal is one of the key devices in all-solid-state laser technology, and borate halides show outstanding potential due to their abundant structural diversity and short UV cut-off edges. In this article, the sizable UV NLO crystal of $\mathrm{K}_{3} \mathrm{~B}_{6} \mathrm{O}_{10} \mathrm{Br}(\mathrm{KBOB})$ has been grown with lead-containing and lead-free fluxes systems using the high-temperature top-seeded solution growth (TSSG) method. Energy Dispersive X-ray Spectroscopy (EDS) and transmittance spectra illustrate the influence of $\mathrm{Pb}^{2+}$ ions on the transmittance properties and laser-induced damage threshold (LDT). The thermal property, namely, thermal expansion, thermal conductivity, and thermal diffusivity curves, were characterized. Moreover, a small variation of thermal refractive indexes was analyzed to illustrate the advantage of $\mathrm{KBOB}$ in the application for temperature-fluctuated specific regions.
\end{abstract}

Keywords: top-seeded solution growth; $\mathrm{K}_{3} \mathrm{~B}_{6} \mathrm{O}_{10} \mathrm{Br}$; nonlinear optical crystal; lead-free fluxes; optical property; thermal property

\section{Introduction}

Due to the good monochromaticity, strong directivity, and high brightness, lasers have been used extensively in the fields of industry, communication, and information technology, through applications such as laser welding, laser etching, and free special optical. Benefiting from the frequency conversion by NLO crystals, a UV laser can be expediently and efficiently obtained [1-4]. Nowadays, some well-known borates, such as $\beta-\mathrm{BaB}_{2} \mathrm{O}_{4}(\beta-\mathrm{BBO})$ [5], $\left(\mathrm{LiB}_{3} \mathrm{O}_{5}\right)(\mathrm{LBO})[6], \mathrm{CsLiB}_{6} \mathrm{O}_{10}$ (CLBO) [7] have been commercially applied. While these classic crystals cannot meet practical needs, the investigation of NLO crystals with a UV absorption deeper than $400 \mathrm{~nm}$, a large second harmonic generation (SHG) response, and a moderate birefringence is of urgent demand.

Notably, introducing halide elements into borate can regulate the structure configuration and increase the structure diversity, and this strategy leads to the discovery of plenty of excellent UV NLO materials [8-12]. In 2006, KBOB was firstly synthesized by Belokoneva et al. via the hydrothermal method [13], which crystalized in the $R 3 m$ space group. Then, centimeter-sized KBOB crystals were grown by our group via the high-temperature TSSG method using lead-containing fluxes to reduce the crystallizing temperature and hinder the volatilization of bromine [14-16]. The property characterizations of the crystal indicates that KBOB crystals have a short UV absorption edge (about $182 \mathrm{~nm}$ ), large SHG response $\left(\mathrm{d}_{22}=0.83 \mathrm{pm} / \mathrm{V}\right)$, moderate birefringence $(0.0506 @ 355 \mathrm{~nm})$, and short type I phase-matching SHG wavelength $(290 \mathrm{~nm})$, which was regarded as a potential UV NLO crystal. Due to the thriving performance, R.K. Li et al. [17-19] continued the growth of $\mathrm{KBOB}$ and estimated the optical properties. The autonomous studies by these groups verified the promising application of $\mathrm{KBOB}$ crystals for laser frequency conversion in the UV 
region, such as $355 \mathrm{~nm}$ laser outputting by frequency tripling of Nd: YAG. However, in the previous sizable growth of $\mathrm{KBOB}$, the lead-containing fluxes were adopted to decrease the viscosity and crystallization temperature of the solution. At the same time, the introduction of $\mathrm{Pb}^{2+}$ cations causes UV absorption below $280 \mathrm{~nm}$. Although decreasing the content of the $\mathrm{PbO}$ in the flux can reduce absorption, the issue remains unsolved [17]. Hence, we propose the exploration of lead-free fluxes to completely remove the absorption and propose the dominant application fields of KBOB crystal.

In this article, we present research regarding growing the $\mathrm{KBOB}$ crystal to analyze the difference of optical absorption between lead-containing and lead-free fluxes systems. Additionally, the thermal expansion, thermal conductivity, thermal diffusivity, and thermal refractive index of KBOB were compared with the benchmark UV NLO crystal LBO. The results indicate that $\mathrm{KBOB}$ is preponderant in the circumstance with temperature fluctuation due to the weak temperature dependence of physical properties of KBOB.

\section{Materials and Methods}

KBOB has been grown by the top-seeded solution growth (TSSG) method as KBOB melts incongruently. All of the regents are analytically pure and were used as received. The method to grow $\mathrm{KBOB}$ with lead-containing fluxes (KBOB-L) can be found in a previously published article. For the lead-free fluxes (KBOB-LF), $\mathrm{H}_{3} \mathrm{BO}_{3}, \mathrm{KBr}, \mathrm{K}_{2} \mathrm{CO}_{3}$, and $\mathrm{KF}$ were mixed in the proper molar ratio and pre-calcined, then the mixture was transferred to the center of a vertical, programmable temperature furnace with a platinum plate to restrain the volatilization and heated to at $740{ }^{\circ} \mathrm{C}$ for $24 \mathrm{~h}$. Then, the temperature was rapidly cooled to $720^{\circ} \mathrm{C}$, and a seed crystal was dipped into the solution. After this operation, the rotation speed of the seed crystal was set to $20 \mathrm{rpm}$, and the cooling rate was set as $0.1^{\circ} \mathrm{C}$ per day. Finally, a crystal with the size of $25 \mathrm{~mm} \times 10 \mathrm{~mm} \times 30 \mathrm{~mm}$ was obtained, and the experiment was completed by removing the crystal from the solution.

The powder X-ray diffraction (PXRD) was recorded by Bruker's D2 PHASER XRD diffractometer (Germany) at room temperature. The sample was ground and placed in the instrument. Comparing the results with the powder diffraction file (PDF) cards in Jade helped to identify the composition of the powder.

The energy dispersive X-ray spectrum of the crystals was recorded by OXFORD INSTRUMENTS X-MaxN's (Britain) microscopic analysis instrument consisting of SEM (Scanning Electron Microscope) and EDS. A piece of crystal was taken from the bulk crystal and was placed in the equipment to be tested.

The transmittance spectrum was recorded by Shimadzu SolidSpec-3700 DUV UV-VISIR spectrometer (Japan) at room temperature, and the measurement range extends from $180 \mathrm{~nm}$ to $1600 \mathrm{~nm}$. Polished crystal plates of KBOB-L and KBOB-LF were used in the characterization.

The thermal expansion coefficients were measured with a thermal-mechanical analyzer (Netzsch DIL402PC, Germany). Two crystal plates, oriented in the direction of [100] and [001], respectively, were used to study the thermal expansion coefficients of $\mathrm{KBOB}$ along the different crystallographic axis. The measuring directions of the crystal plates were polished to $4.359 \mathrm{~mm}$ and $5.017 \mathrm{~mm}$, respectively. The thermal conductivity and thermal diffusion coefficient were tested by laser thermal conductivity analyzer (Netzsch LFA 457, Netzsch, Selb, Germany).

The thermal refractive index of $\mathrm{KBOB}$ was measured using the prism coupling technique (Metricon Model 2010, Metricon, Pennington, NJ, USA), and a [001] crystal plate was used for the test at temperatures of $25,40,60,80$, and $100^{\circ} \mathrm{C}$, respectively.

The LDT was measured on a pulsed Q-switched Nd: YAG laser (Continuum, $1064 \mathrm{~nm}$, $5 \mathrm{~ns}, 10 \mathrm{~Hz}$ ) using KBOB-L and KBOB-LF crystal plates with $1 \mathrm{~mm}$ thickness. An optical concave lens was used to obtain the appropriate laser beam diameter $(0.5 \mathrm{~mm})$.

The rocking curves were recorded by a high-resolution X-Ray Diffractometer (D2 phaser, Germany), using polished KBOB-L and KBOB-LF crystal plates with the size of $5 \mathrm{~mm} \times 5 \mathrm{~mm} \times 1 \mathrm{~mm}$. 


\section{Results and Discussion}

\subsection{The Crystal Growth of KBOB with Lead-Containing and Lead-Free Fluxes}

The following reagents were purchased and were not further purified: $\mathrm{H}_{3} \mathrm{BO}_{3}$ (Aladdin, Shanghai, China, 99.99\%), KBr (Aladdin, Shanghai, China, 99.99\%), KF (Tianjin Hengxing, Tianjin, China, $\geq 99.0 \%$ ), $\mathrm{PbO}$ (Aladdin, Shanghai, China, 99.9\%), $\mathrm{K}_{2} \mathrm{CO}_{3}$ (Tianjin Hengxing, Tianjin, China, $\geq 99.0 \%$ ), $\mathrm{KF} \cdot 2 \mathrm{H}_{2} \mathrm{O}$ (Tianjin Hengxing, Tianjin, China, $\geq 99.0 \%$ ).

For the KBOB-L (the ratio of the raw materials was $\mathrm{H}_{3} \mathrm{BO}_{3}: \mathrm{KBr}: \mathrm{KF}: \mathrm{PbO}=6: 1: 2: 1$ ), the orientation of the seed crystal was selected as described in [101], and a high-quality, transparent crystal $(30 \mathrm{~mm} \times 30 \mathrm{~mm} \times 10 \mathrm{~mm})$ with the developing faces of [101], [211], and [110] was obtained (Figure 1a). The volatile was collected and characterized, and the result indicates that the volatile mixture consists of $\mathrm{PbBr}_{2}, \mathrm{PbBrF}$, and $\mathrm{KPb}_{2} \mathrm{Br}_{5}$. At the same time, the prior fluxes used were, the self-fluxes for the TSSG method to avoid introducing the impurities. Our group explored the fluxes in the system of $\left[\mathrm{H}_{3} \mathrm{BO}_{3}-\mathrm{KBr}-\right.$ $\mathrm{KF}$, [ $\left.\mathrm{H}_{3} \mathrm{BO}_{3}-\mathrm{KBr}-\mathrm{K}_{2} \mathrm{CO}_{3}-\mathrm{KF}\right],\left[\mathrm{H}_{3} \mathrm{BO}_{3}-\mathrm{KBr}_{2} \mathrm{~K}_{2} \mathrm{CO}_{3}-\mathrm{KF} \cdot 2 \mathrm{H}_{2} \mathrm{O}\right.$, and $\left[\mathrm{B}_{2} \mathrm{O}_{3}-\mathrm{KBr}-\mathrm{K}_{2} \mathrm{CO}_{3}-\mathrm{KF}\right.$, respectively. Speculated from the experiment results, $\left[\mathrm{H}_{3} \mathrm{BO}_{3}-\mathrm{KBr}-\mathrm{K}_{2} \mathrm{CO}_{3}-\mathrm{KF}\right]$ was the best growing system, as the main phase of the crystallization product was $\mathrm{KBOB}$. Finally, the ratio of $\mathrm{H}_{3} \mathrm{BO}_{3}: \mathrm{KBr}_{2} \mathrm{~K}_{2} \mathrm{CO}_{3}: \mathrm{KF}$ was selected as 6:0.6:0.5:1, Additionally, a block $\mathrm{KBOB}$ crystal with the size of $25 \mathrm{~mm} \times 10 \mathrm{~mm} \times 30 \mathrm{~mm}$ was obtained (Figure 1b). Apparently, the inclusion was found in the crystal, which is due to the heavy volatilization, (Mainly potassium bromide) leading to deviated components at the high growth temperature. The transmittance spectra indicate that the KBOB-LF performs better than KBOB-L in the UV region (Figure 1c) due to the absence of lead compounds. Specifically, the removal of lead can result in a $70 \mathrm{~nm}$ blueshift, which is effective for application in shortwave regions, for example, $266 \mathrm{~nm}$ laser frequency doubling via sum-frequency. Hence, the optimized growth technique, such as the closed high-temperature solution method, needs to be developed to prevent volatilization in future studies. We recorded the PXRD of KBOB-L and KBOB-LF, and both of were in accordance with those that were calculated (Figure 2a). The Raman bands (Figure $2 \mathrm{~b}$ ) around $1011-1159 \mathrm{~cm}^{-1}$ can be attributed to the $\mathrm{BO}$ stretching vibrations of both the trigonal and tetrahedral boron, and the bands located from $600 \mathrm{~cm}^{-1}$ to $800 \mathrm{~cm}^{-1}$ are attributed to the bending modes of trigonal and tetrahedral boron, which means both KBOB-L and KBOB-LF consisted of the ideal KBOB structure.
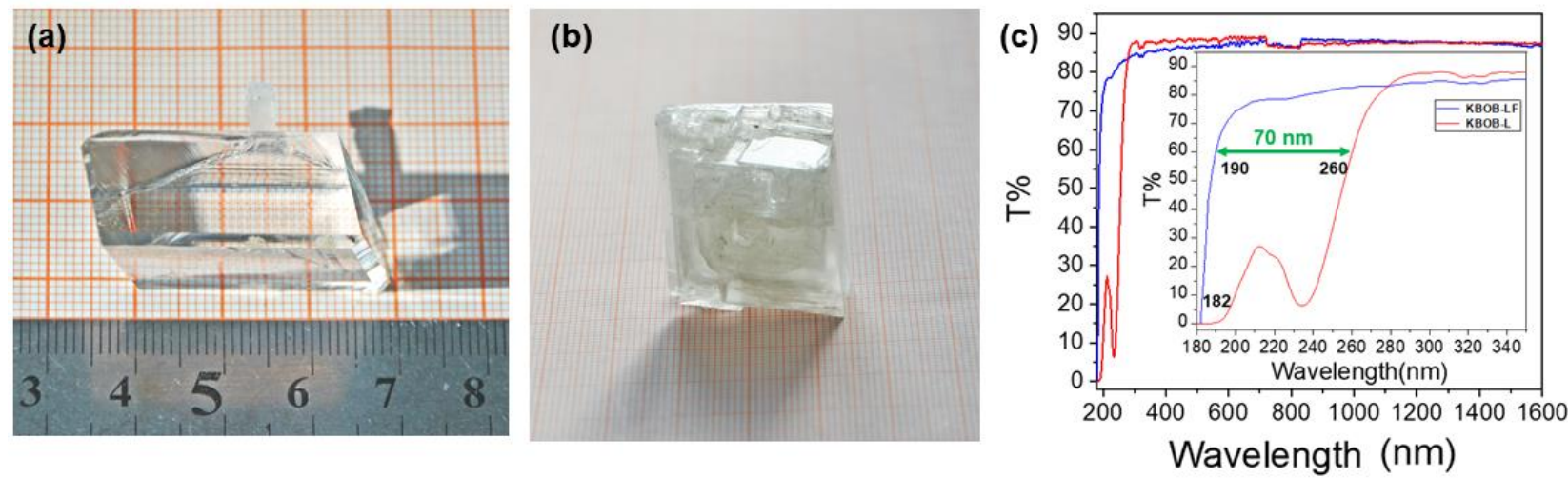

Figure 1. $(\mathbf{a}, \mathbf{b})$ The photographs of KBOB-L and KBOB-LF crystals, respectively. (c) The transmittance spectra of KBOB-LF and KBOB-L, respectively. 

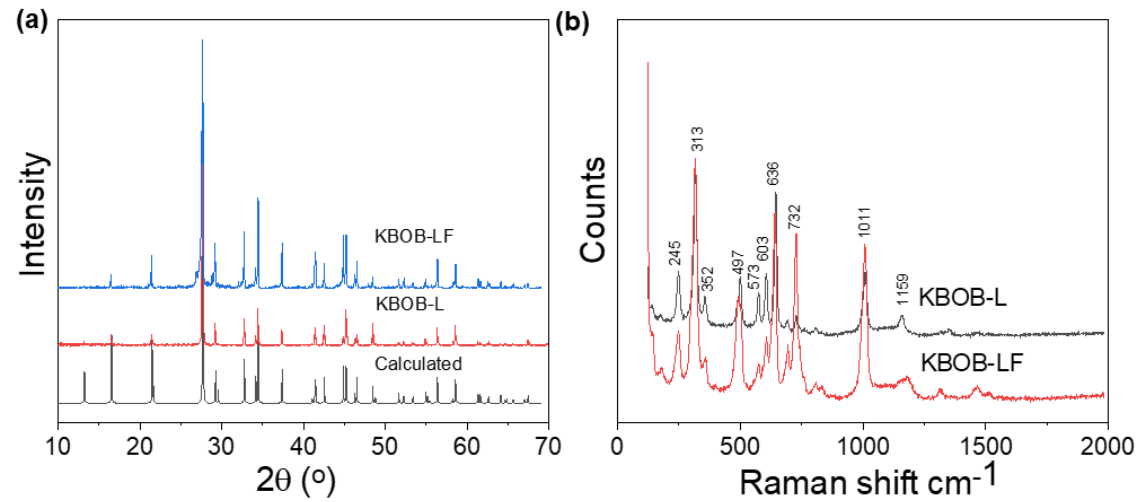

Figure 2. (a) The XRD patterns and (b) the Raman spectra of KBOB-L and KBOB-LF crystals, respectively.

\subsection{The EDS Analysis of $K B O B$ Crystals}

In order to identify whether the fluxes, especially for the non-self fluxes, intrude into the crystal lattice as doped ions, EDS tests were performed to investigate the quantity and distribution of the elements (Figure 3). The abundance of the elements is uniformly distributed, which means the crystals are of high quality. When $\mathrm{PbO}$ flux was used, the lead ion was found to be distributed homogeneously in the transparent zone of KBOB-L, which means that the impurity ions were relatively evenly distributed in the crystal lattices. Furthermore, the distribution of lead and fluorine ions was localized in the inclusion zone (Figure 4). Although the concentrations of lead ions are very low, they significantly influence the optical performance, such as the transmittance in the UV region. For KBOB-LF, the main elements are $\mathrm{K}, \mathrm{B}, \mathrm{O}$, and $\mathrm{Br}$ (Figure 5), and no other impurity elements were found. This means that the objective of removing the absorption in the UV region caused by the $\mathrm{Pb}$ element was achieved.

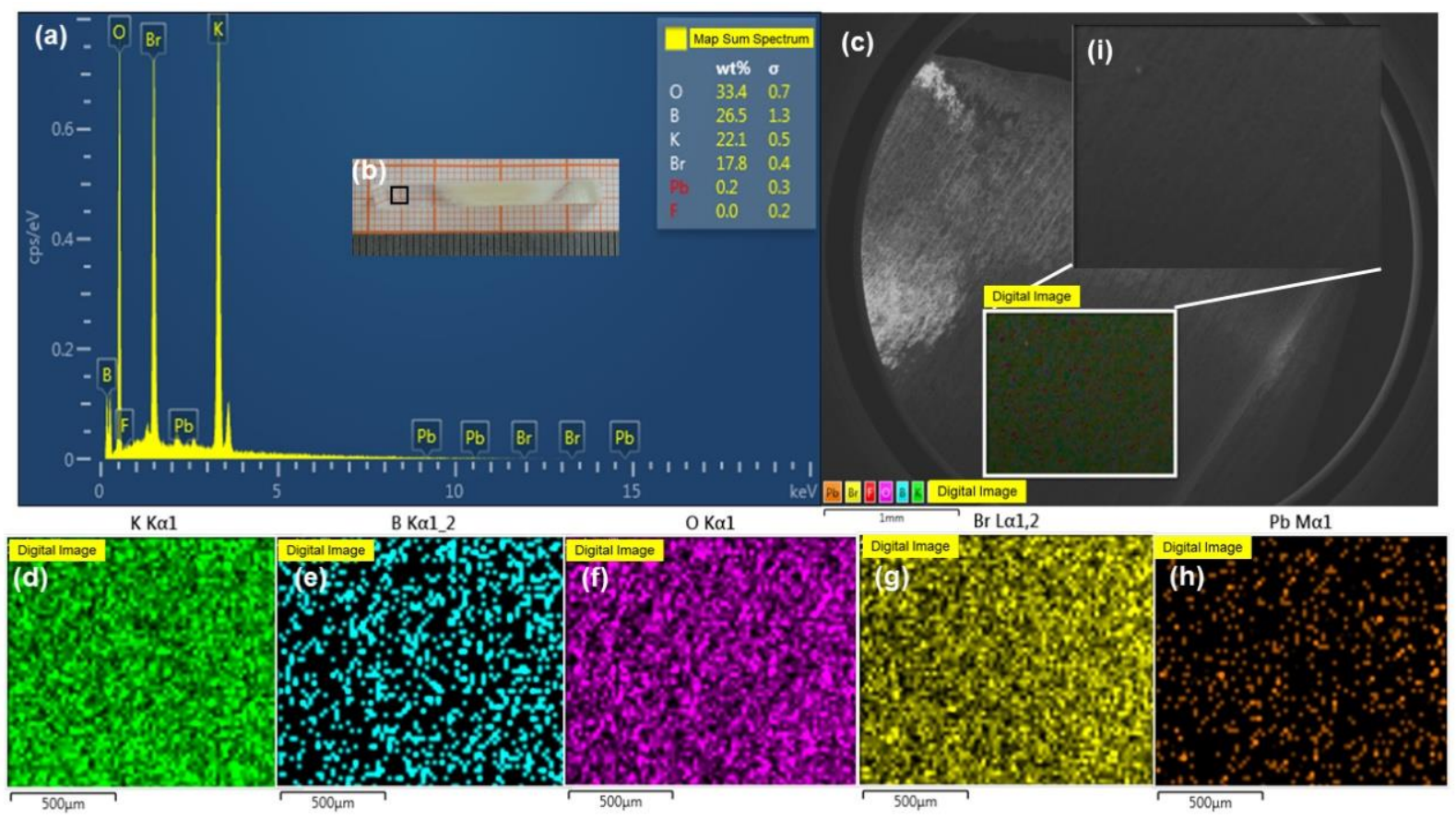

Figure 3. Element analysis of the transparent zone of KBOB-L. (a) Element analysis photography. (b) The picture of KBOB crystal (c) Surface topography photography. (d-g), and (h) EDS digital images of elements $\mathrm{K}, \mathrm{B}, \mathrm{O}, \mathrm{Br}$, and $\mathrm{Pb}$, respectively. (i) The SEM photograph of the transparent zone of KBOB-L. 


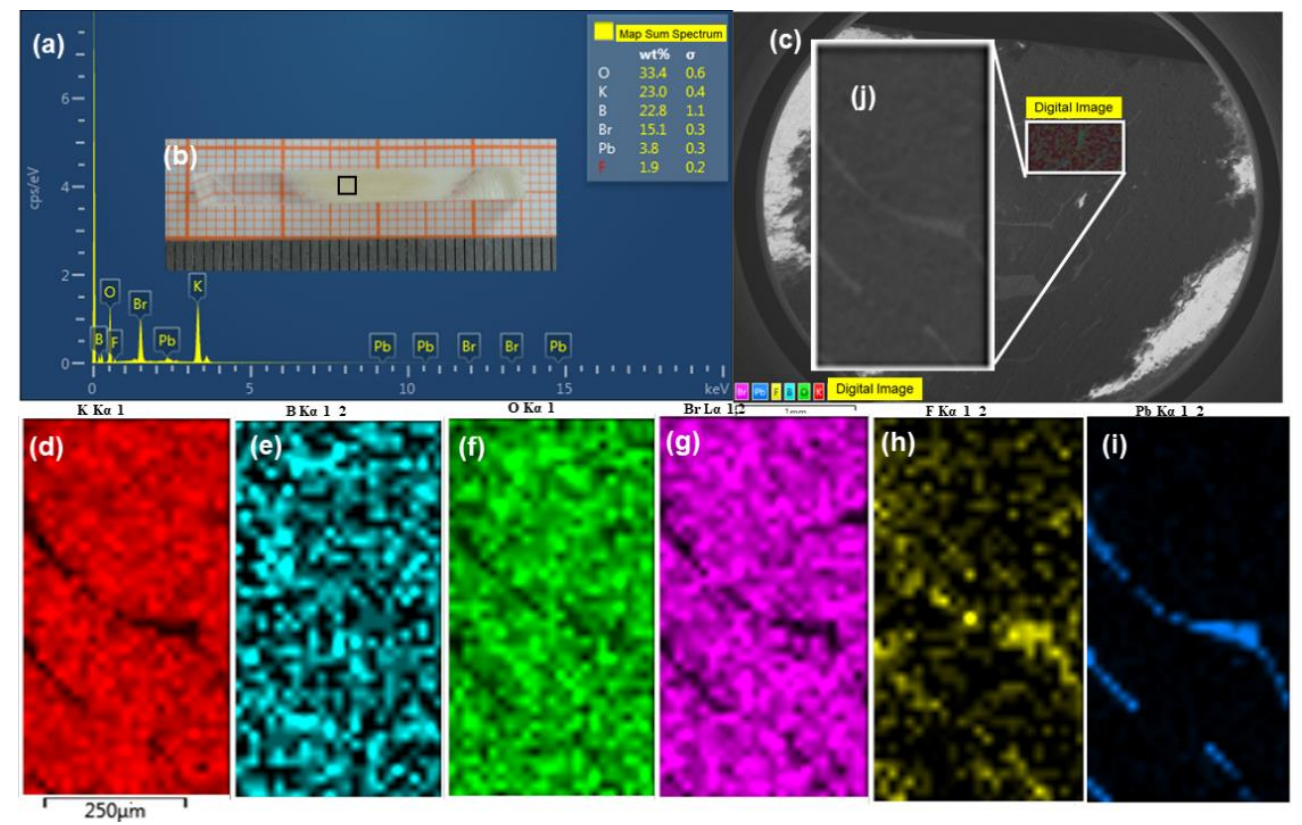

Figure 4. Element analysis of the inclusion zone of KBOB-L. (a) Element analysis photography. (b) The picture of KBOB crystal (c) Surface topography photography. (d-h), and (i) EDS digital images of elements $\mathrm{K}, \mathrm{B}, \mathrm{O}, \mathrm{Br}, \mathrm{F}$, and $\mathrm{Pb}$, respectively. (j) The SEM photograph of the inclusion zone KBOB-L.
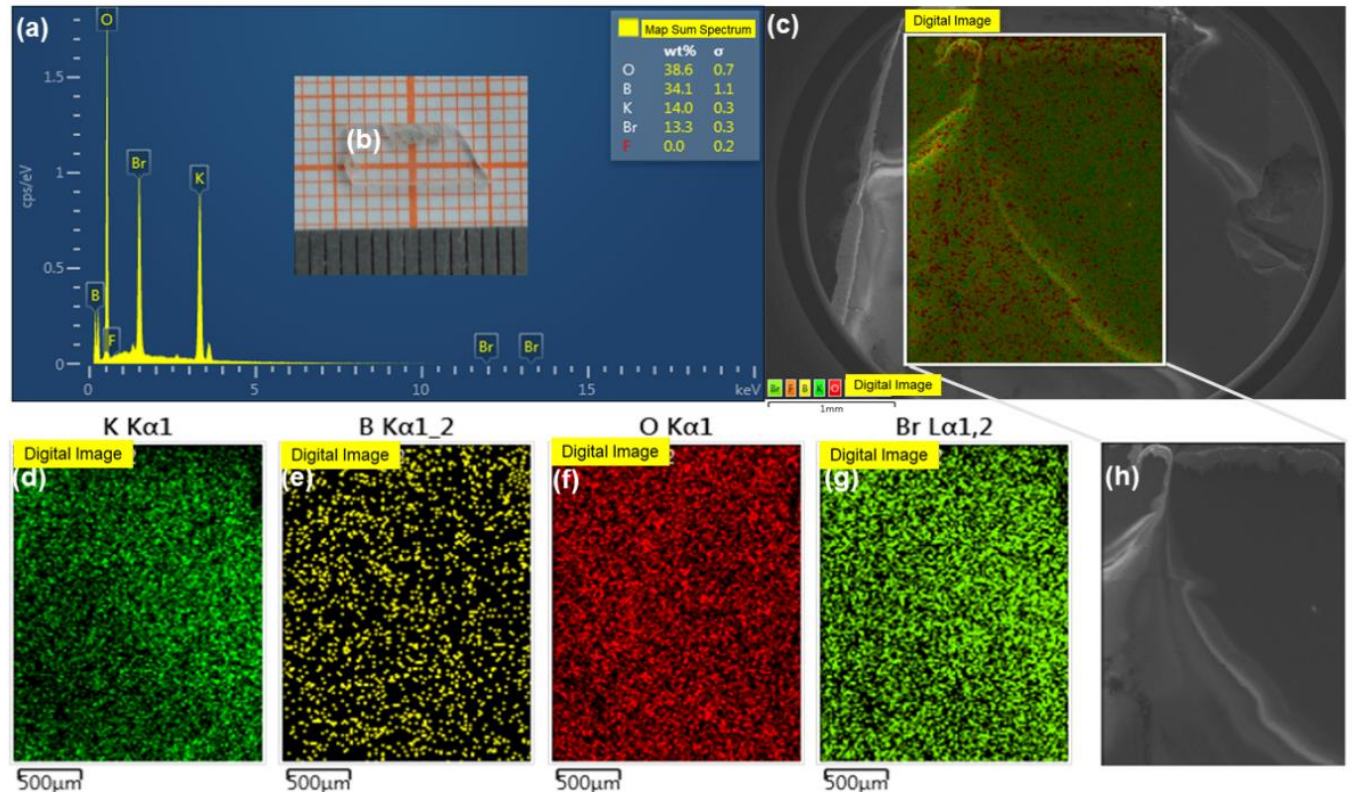

Figure 5. Element analysis of KBOB-LF. (a) Element analysis photography. (b) The object picture of KBOB crystal (c) Surface topography photography (d-g) EDS digital images of elements K, B, O, and Br, respectively. (h) The SEM photograph of KBOB-LF.

\subsection{Rocking Curves and Laser Damage Threshold}

Both of the rocking curves of KBOB-LF and KBOB-L have ideal symmetric shapes, and the full width at half maximum (FWHM) is relatively small, at $30.706^{\prime \prime}$ and $28.044^{\prime \prime}$, respectively, which means both of these two crystals are of high quality (Figure 6). 
(a)

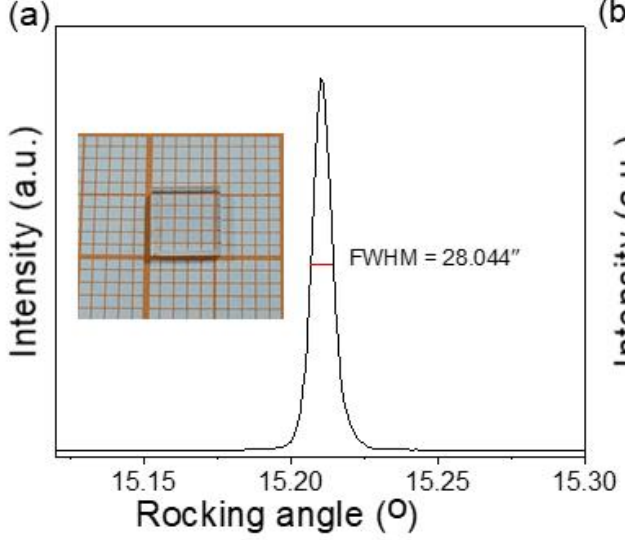

(b)

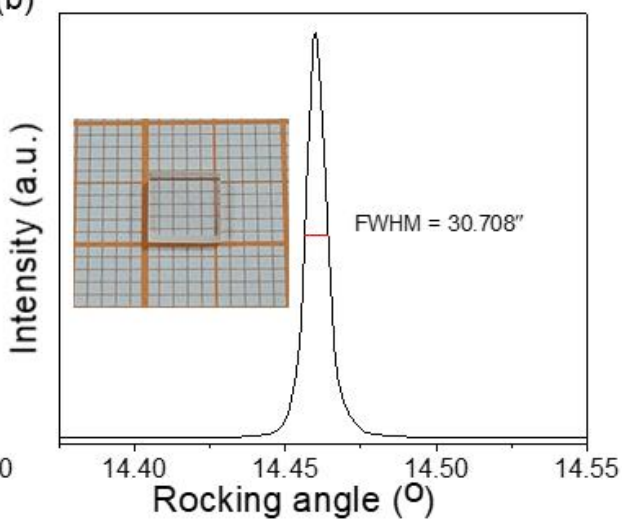

Figure 6. $(\mathbf{a}, \mathbf{b})$ the rocking curves of KBOB-L and KBOB-LF, respectively.

Additionally, the LDTs of KBOB-LF and KBOB-L are 2.5 and $1.4 \mathrm{GW} \cdot \mathrm{cm}^{-2}$, respectively, which means that the lead impurity can cause absorption and significantly affect the laser's damage resistance.

\subsection{The Thermal Properties}

The thermal expansion coefficients $(\alpha)$ of $\mathrm{KBOB}$ in different directions are $\alpha_{[100]}=8.84$ $\times 10^{-6} / \mathrm{K}$, and $\alpha_{[001]}=13.86 \times 10^{-6} / \mathrm{K}$, respectively (Figure 7). The ratio of the thermal expansion coefficients between the $\mathrm{c}$ direction and a direction is 1.6, which is relatively smaller than $\mathrm{LBO}\left(\alpha_{[100]}=66.4 \times 10^{-6} / \mathrm{K}, \alpha_{[001]}=-52.8 \times 10^{-6} / \mathrm{K}\right.$, and $\alpha_{[110]}=27.3 \times 10^{-6} / \mathrm{K}$, respectively [20]). The thermal conductivity and thermal diffusivity were also considered for the applied perspective of the crystals, and these properties are shown in Figure $7 \mathrm{~b}$. Both of them decrease with increasing temperature, and the values of different crystallographic axis were kept approximate, which is beneficial for the uniform distribution of heat in different directions. The small thermal anisotropy of $\mathrm{KBOB}$ is beneficial for avoiding cracks in the process of crystal growth and application in laser devices.
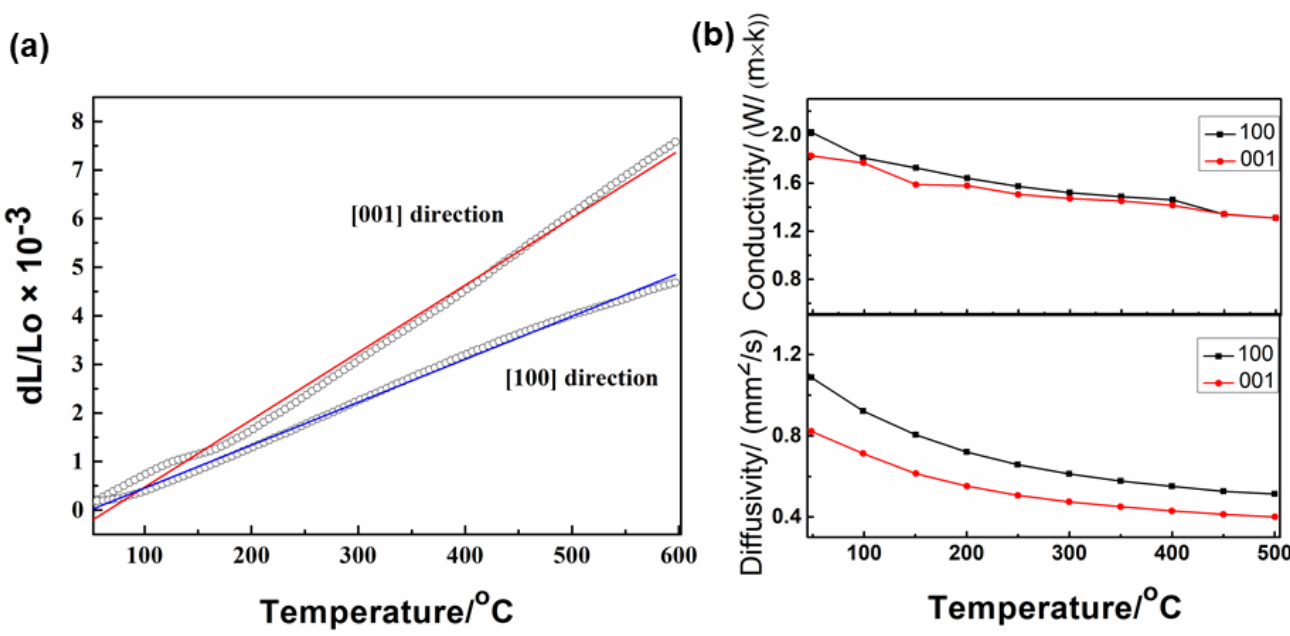

Figure 7. (a) Thermal expansion curves, (b) thermal conductivity curves, and thermal diffusivity curves of $\mathrm{KBOB}$ crystal along the different crystallographic axis.

\subsection{Thermal Refractive Index}

As the heating effect of the laser system, the thermal refractive index is very important for the application. As shown in Table 1, the refractive index waned slightly with the increased temperature, as did the birefringence. Then, the Sellmeier equation was fitted to map the curves of the type I phase matching angle (frequency-doubling of Nd: YAG laser) versus temperature (Figure 8). It is clear that the phase-matching angles of KBOB changed 
slightly (about $0.5^{\circ}$ ) when the temperature ranged from $25^{\circ} \mathrm{C}$ to $100^{\circ} \mathrm{C}$. This suggests that the NLO property of $\mathrm{KBOB}$ is less affected by temperature, and it is not necessary to use the temperature control system during the frequency doubling applications, which is of benefit to the miniaturization of the equipment system and for applications in temperaturefluctuated circumstances.

Table 1. Thermal refractive index at different temperatures.

\begin{tabular}{|c|c|c|c|c|c|c|}
\hline \multicolumn{2}{|c|}{$\lambda(\mu \mathrm{m}) / \mathrm{T}\left({ }^{\circ} \mathrm{C}\right)$} & 25 & 40 & 60 & 80 & 100 \\
\hline \multirow{3}{*}{0.405} & $n_{o}$ & 1.60344 & 1.60301 & 1.60259 & 1.60220 & 1.60179 \\
\hline & $n_{e}$ & 1.55386 & 1.55394 & 1.55357 & 1.55317 & 1.55303 \\
\hline & $n_{o}-n_{e}$ & 0.04958 & 0.04907 & 0.04902 & 0.04903 & 0.04876 \\
\hline \multirow{3}{*}{0.514} & $n_{0}$ & 1.59120 & 1.59098 & 1.59071 & 1.59030 & 1.59014 \\
\hline & $n_{e}$ & 1.54350 & 1.54340 & 1.54299 & 1.54282 & 1.54260 \\
\hline & $n_{o}-n_{e}$ & 0.04770 & 0.04758 & 0.04772 & 0.04748 & 0.04754 \\
\hline \multirow{3}{*}{0.636} & $n_{o}$ & 1.58358 & 1.58340 & 1.58320 & 1.58280 & 1.58251 \\
\hline & $n_{e}$ & 1.53652 & 1.53630 & 1.53624 & 1.53602 & 1.53599 \\
\hline & $n_{o}-n_{e}$ & 0.04706 & 0.04710 & 0.04696 & 0.04678 & 0.04652 \\
\hline \multirow{3}{*}{0.965} & $n_{o}$ & 1.57488 & 1.57456 & 1.57444 & 1.57412 & 1.57390 \\
\hline & $n_{e}$ & 1.52895 & 1.52934 & 1.52886 & 1.52868 & 1.52856 \\
\hline & $n_{o}-n_{e}$ & 0.04593 & 0.04522 & 0.04558 & 0.04544 & 0.04534 \\
\hline \multirow{3}{*}{1.547} & $n_{o}$ & 1.56611 & 1.56542 & 1.56531 & 1.56517 & 1.56490 \\
\hline & $n_{e}$ & 1.52193 & 1.52182 & 1.52179 & 1.52170 & 1.52135 \\
\hline & $n_{o}-n_{e}$ & 0.04418 & 0.04360 & 0.04352 & 0.04347 & 0.04355 \\
\hline
\end{tabular}

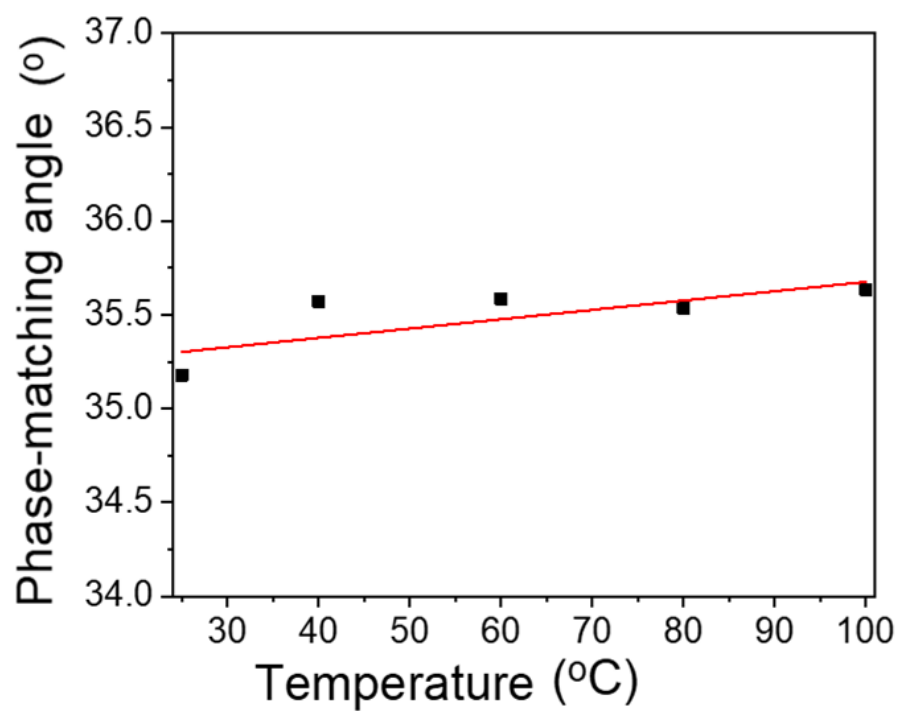

Figure 8. The type I phase-matching angles of $\mathrm{KBOB}$ at different temperatures.

\section{Conclusions}

In conclusion, the UV NLO crystal, KBOB, has been grown by the TSSG method with lead-containing and lead-free fluxes, respectively. The lead impurities in the crystal lattice cause UV absorption below $280 \mathrm{~nm}$, and the problem was solved by exploring lead-free fluxes. The UV absorption edge of KBOB-LF has a blueshift of $70 \mathrm{~nm}$ above KBOB-L. The small differences in the thermal expansion, thermal conductivity, and thermal diffusivity between different crystallographic axes endow KBOB with excellent mechanical properties 
for wafer fabrication and application. Moreover, the KBOB crystals' refractive indexes show weak temperature dependence, which indicates that KBOB crystals can avoid phase mismatching with temperature severely changing. Hence, KBOB is a potential material for the application in UV nm laser frequency doubling. Notably, upgraded equipment needs to be developed to restrain volatilization during the growth of KBOB-LF.

Author Contributions: The manuscript was written through the contributions of all authors. M.Z. conceptualized and designed the experiment. H.H., C.Z., J.J., S.G. and Y.C. performed the entire experiment and analyzed the results. H.H. wrote the manuscript. M.Z. revised the manuscript. All authors have read and agreed to the published version of the manuscript.

Funding: This research was funded by the Youth Innovation Promotion Association of CAS (2020429), the CAS Project for Young Scientists in Basic Research (YSBR-024), the National Natural Science Foundation of China (22122509, 52002398, and 11774414), and the Xinjiang Major Science and Technology Project (2021A01001-3).

Institutional Review Board Statement: Not applicable.

Informed Consent Statement: Not applicable.

Conflicts of Interest: The authors declare no conflict of interest.

\section{References}

1. Zhang, W.G.; Yu, H.W.; Wu, H.P.; Halasyamani, P.S. Crystal Growth and Associated Properties of a Nonlinear Optical Crystal$\mathrm{Ba}_{2} \mathrm{Zn}\left(\mathrm{BO}_{3}\right)$. Crystals 2016, 6, 68. [CrossRef]

2. Chen, Q.L.; Luo, M.; Lin, C.S. $\mathrm{Na}_{4} \mathrm{Yb}\left(\mathrm{CO}_{3}\right)_{3} \mathrm{~F}$ : A New UV Nonlinear Optical Material with a Large Second Harmonic Generation Response. Crystals 2018, 8, 381. [CrossRef]

3. Zou, G.H.; Lin, C.S.; Kim, H.G.; Jo, H.; OK, K.M. $\mathrm{Rb}_{2} \mathrm{Na}\left(\mathrm{NO}_{3}\right)_{3}$ : A congruently Melting UV-NLO Crytal with a Very Strong Second-Harmonic Generation Response. Crystals 2016, 6, 42. [CrossRef]

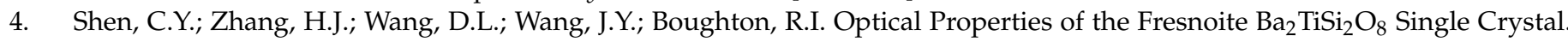
Crystals 2017, 7, 53. [CrossRef]

5. Fedorov, P.P.; Kokh, A.E.; Kononova, N.G. Barium borate $\beta-\mathrm{BaB}_{2} \mathrm{O}_{4}$ as a material for nonlinear optics. Russ. Chem. Rev. 2002, 71, 651-671. [CrossRef]

6. Lin, S.J.; Sun, Z.Y.; Wu, B.C.; Chen, C.T. The nonlinear optical characteristics of a $\mathrm{LiB}_{3} \mathrm{O}_{5}$ crystal. J. Appl. Phys. 1990, 67, 634-638. [CrossRef]

7. Sasaki, T.; Mori, Y.; Yoshimura, M. Progress in the growth of a $\mathrm{CsLiB}_{6} \mathrm{O}_{10}$ crystal and its application to ultraviolet light generation. Opt. Mater. 2003, 23, 343-351. [CrossRef]

8. Wu, H.P.; Pan, S.L.; Poeppelmeier, K.R.; Li, H.Y.; Jia, D.Z.; Chen, Z.H.; Fan, X.Y.; Yang, Y.; Rondinelli, J.M.; Luo, H.S. K ${ }_{3} B_{6} \mathrm{O}_{10}$ Cl: A New Structure Analogous to Perovskite with a Large Second Harmonic Generation Response and Deep UV Absorption Edge. J. Am. Chem. Soc. 2011, 133, 7786-7790. [CrossRef] [PubMed]

9. Liu, H.K.; Wang, Y.; Zhang, B.B.; Yang, Z.H.; Pan, S.L. CsAlB ${ }_{3} \mathrm{O}_{6}$ F: A beryllium-free deep-ultraviolet nonlinear optical material with enhanced thermal stability. Chem. Sci. 2019, 11, 694-698. [CrossRef] [PubMed]

10. Yu, H.W.; Young, J.S.; Wu, H.P.; Zhang, W.G.; Rondinelli, J.M.; Halasyamani, S. The Next-Generation of Nonlinear Optical Materials: $\mathrm{Rb}_{3} \mathrm{Ba}_{3} \mathrm{Li}_{2} \mathrm{Al}_{4} \mathrm{~B}_{6} \mathrm{O}_{20} \mathrm{~F}$-Synthesis, Characterization, and Crystal Growth. Adv. Opt. Mater. 2017, 5, 1700840. [CrossRef]

11. Wu, B.C.; Tang, D.Y.; Ye, N.; Chen, C.T. Linear and nonlinear optical properties of the $\mathrm{KBe}_{2} \mathrm{BO}_{3} \mathrm{~F}_{2}(\mathrm{KBBF}) \mathrm{crystal}$. Opt. Mater. 1996, 5, 105-109. [CrossRef]

12. Mutailipu, M.; Zhang, M.; Wu, H.P.; Yang, Z.H.; Shen, Y.H.; Sun, J.L.; Pan, S.L. $\mathrm{Ba}_{3} \mathrm{Mg}_{3}\left(\mathrm{BO}_{3}\right)_{3} \mathrm{~F}_{3}$ polymorphs with reversible phase transition and high performances as ultraviolet nonlinear optical materials. Nat. Commun. 2018, 9, 3089. [CrossRef] [PubMed]

13. Al-Ama, A.G.; Belokoneva, E.L.; Stefanovich, S.Y.; Dimitrova, O.V.; Mochenova, N.N. Potassium Bromo-Borate $\mathrm{K}_{3}\left[\mathrm{~B}_{6} \mathrm{O}_{10}\right] \mathrm{Br}-\mathrm{A}$ New Nonlinear Optical Material. Crystallogr. Rep. 2006, 51, 225-230. [CrossRef]

14. Zhang, M.; Pan, S.L.; Fan, X.Y.; Zhou, Z.X.; Poeppelmeier, K.R.; Yang, Y. Crystal growth and optical properties of a noncentrosymmetric haloid borate, $\mathrm{K}_{3} \mathrm{~B}_{6} \mathrm{O}_{10}$ Br. CrystEngComm 2011, 13, 2899-2903. [CrossRef]

15. Zhang, M.; Su, X.; Pan, S.L.; Wang, Z.; Zhang, H.; Yang, Z.H.; Zhang, B.B.; Dong, L.Y.; Wang, Y.; Zhang, F.F.; et al. Linear and Nonlinear Optical Properties of $\mathrm{K}_{3} \mathrm{~B}_{6} \mathrm{O}_{10} \mathrm{Br}$ Single crystal: Experiments and Calculation. J. Phys. Chem. C 2014, 118, 11849-11856. [CrossRef]

16. Fan, X.Y.; Zhang, M.; Pan, S.L.; Yang, Y.; Zhao, W.W. Top seeded solution growth and optical properties of a bromic borate crystal: $\mathrm{K}_{3} \mathrm{~B}_{6} \mathrm{O}_{10}$ Br. Mater. Lett. 2012, 68, 374-377. [CrossRef]

17. Xia, M.J.; Xu, B.; Li, R.K. Growth and nonlinear optical properties of $\mathrm{K}_{3} \mathrm{~B}_{6} \mathrm{O}_{10} \mathrm{Br}$ crystal. J. Cryst. Growth 2014, 404, 65-68. [CrossRef] 
18. Xia, M.J.; Xu, B.; Liu, L.J.; Wang, X.Y.; Li, R.K.; Chen, C.T. Thermo-physical properties of nonlinear optical crystal $\mathrm{K}_{3} \mathrm{~B}_{6} \mathrm{O}_{10} \mathrm{Br}$ J. Appl. Cryst. 2016, 49, 539-543. [CrossRef]

19. Meng, L.P.; Zhang, L.; Hou, Z.Y.; Wang, L.R.; Xu, H.; Shi, M.; Wang, L.W.; Yang, Y.Y.; Qi, Y.Y.; He, C.J.; et al. Frequency-doubled green picosecond laser based on K3B6O10Br nonlinear optical crystal. Optlastec 2018, 101, 401-403. [CrossRef]

20. Guo, R.Y.; Markgraf, S.A.; Furukawa, Y.; Sato, M.; Bhalla, A.S. Pyroelectric, dielectric, and piezoelectric properties of $\mathrm{LiB}_{3} \mathrm{O}_{5}$. J. Appl. Phys. 1995, 78, 7234-7239. [CrossRef] 